\title{
Research on the Promotion Path of College Students' Media Literacy Education Under the Self- Media Environment
}

\author{
Lei Zhang1*, Kang Ye ${ }^{2}$ \\ 1Yulin University, Yulin 719000, Shaanxi Province, China \\ 2 Yulin Gaoxin No.1 Middle School, Yulin 719000, Shaanxi Province, China \\ *Corresponding author: Lei Zhang, 2015025@yulinu.edu.cn
}

\begin{abstract}
In the era of self-media, information dissemination which is based on independent provision and sharing by ordinary people is characterized by personalization, popularization, immediacy and autonomy, causing a great impact on politics, economy, society and other aspects. In the self-media environment, everyone may become the receiver, creator and sender of media information, which has an important impact on the value formation of college students. College students should have high media literacy, be able to distinguish right from wrong, distinguish true from false, and spread positive energy. Improving media literacy education through a variety of ways is an important way to cultivate talents with morality, high quality, innovative thinking and ability. It helps college students improve themselves better and faster.
\end{abstract}

Keywords: Self-media; Media literacy; Promotion path

Publication date: December 2021; Online publication: January 24, 2022

\section{Introduction}

With the rapid development of digital information technology, self-media represented by the Internet has not only changed the communication and interaction mode of information, but also greatly enriched people's daily life. Self-media is characterized by personalization, popularization, immediacy and autonomy. In the information society, media literacy education should become an important part of college students' quality education. It plays a very important role in improving college students' ideological and moral level. College students' media literacy education has also ushered in new development opportunities and challenges. Colleges and universities should pay attention to the improvement of college students' media literacy education and make progress according to the situation ${ }^{[1]}$.

\section{Practical significance of college students' media literacy in the era of self-media}

\subsection{Strengthening college students' ideological and political education and better adaptation to social life}

Colleges and universities should always adhere to the fundamental goal of building morality and cultivating people, prioritize college students' ideological and political education, and focus on cultivating college students' ideological and moral quality. Through scientific planning, orderly media literacy education and media moral education for college students will help establish correct values, improve their media literacy, guide them to correctly understand self-media, comprehensively improve the effectiveness of college students' ideological and political education, and truly implement the cultivation goal of building morality 
and cultivating people ${ }^{[2]}$.

\subsection{Strengthening the construction of network culture and promoting the innovation of educational forms}

Network culture education is an important carrier of college students' ideological education, which plays a guiding and stimulating role. Therefore, we should deeply explore the important role of network culture construction in college students' media literacy education ${ }^{[3]}$. We should actively carry out the publicity and popularization activities of media literacy. Through diversified activities such as media literacy lectures and quizzes, media literacy education will start to take root in the minds of students, fully improve the attention of college students to media literacy education, correctly guide their scientific analysis of network information, and then improve their awareness of network prevention ${ }^{[4]}$. At the same time, in classroom teaching, teachers can also introduce typical case analysis to encourage students to correctly establish their moral and ethical values, and constantly strengthen the construction of network culture, so as to improve the media literacy level of college students.

\section{Advantages and disadvantages of information explosion in the era of self-media}

\subsection{Optimizing people's daily life}

First, optimize the lifestyle. The use of self-media via mobile network has changed people's daily life, greatly met people's needs in all aspects such as clothing, food, housing and transportation, and saved time to the greatest extent. Second, enrich amateur life. Compared with mass media, self-media brings people diversified content such as mobile news, e-books, audio, video and games, helps people better obtain useful information and improve communication efficiency in work or study, and also delivers leisure in people's free time. Third, deepen people's communication. The emergence of the self-media era has broken the limitations of face-to-face communication. It can also have a deep understanding through mutual attention, sharing and other contents. In the self-media environment, with the understanding of all levels and industries, people have gradually eliminated all kinds of prejudices and misunderstandings and tightened the relationship.

\subsection{Influence of bad information}

First, false information. In order to improve their popularity, some individuals or companies use pictures or videos to fabricate false information for wide dissemination. The source of information is unknown and it is difficult to distinguish between true and false. Second, bad atmosphere. In the era of self-media, people are often influenced by personal information when reading information, so they give up the pursuit of truth. Third, population differentiation. While enriching people's information acquisition methods, self-media also has higher requirements for the ability to distinguish information, but people's ideological consciousness varies, resulting in uneven information acquisition. At the same time, under the influence of big data, people prefer to stay in their own comfort circle and isolate from the outside world, resulting in the differentiation of the population to a certain extent.

\section{Promotion path of college students' media literacy education under the self-media environment}

\subsection{Using media to guide students to realize self-education}

Self-education is an internalization process, which requires independent thinking to improve self-awareness. Therefore, college students should make it clear that they are the subject of educational activities, not the object of forced education. Only in this way can they have correct ideological consciousness ${ }^{[5]}$. Firstly, 
while receiving media literacy education, college students actively strengthen the learning of their knowledge. Only with a profound and rational understanding of exploring things can they grasp the media knowledge. Secondly, we should face the development and change of the self-media era with the best attitude, not blindly follow the trend, not easily affected by the speech of others, and adhere to our own ideological and political position, rationally look at the impact of the media on ourselves and society, and occupy an important position in the process of media utilization. Finally, college students should constantly reflect on the use of self-media, so as to effectively restrict their media participation behavior, and transfer the positive energy to the people around them. The mutual learning and influence between college students can also well promote the expansion and extension of self-education ${ }^{[6]}$.

In the era of self-media, individuals have a greater voice. Everyone can speak freely and enjoy the benefits of the arrival of science and technology. However, everything is a double-edged sword. The wide dissemination of bad information has brought many troubles to people and led college students astray. In this case, relying on the persuasion and intervention by the school and society is difficult. Only when college students realize the importance of media literacy, clarify that media freedom is a responsibility, actively accept the education of media literacy and cultivate their own legal awareness and network morality, they can correct all kinds of changes and troubles brought by the era of self-media, and fundamentally improve their media literacy level ${ }^{[7]}$.

\subsection{Strengthening education and improving teachers' media literacy}

The core of college students' media literacy education is to cultivate students to correctly understand, analyze and use media to serve their own better development. Therefore, teachers play an important role in cultivating students' media literacy, and it is imperative to improve teachers' media literacy ${ }^{[8]}$. First, colleges and universities should constantly improve teachers' attention to media literacy education, not only improve their own knowledge and teaching ability, but also pay attention to the penetration of media literacy into daily education and teaching. Second, the improvement of teachers' media literacy education level is inseparable from their ability to master and use media knowledge. Therefore, colleges and universities do not regularly organize teachers to carry out the cultivation of media knowledge and media literacy. Only teachers who skillfully use media can consciously infiltrate media literacy education in daily teaching.

Similarly, as the direct manager of students, in the current era of self-media, students and managers do not necessarily solve problems face-to-face. Counselors use self-media to manage and provide services to students, and understand the students' situation in time. Therefore, it is very common for counselors to use self-media for management. Media literacy education is not only the knowledge of communication, but also includes psychology, pedagogy and other related knowledge.

\subsection{Improving the system and media literacy}

Media literacy includes psychology, communication and other contents. How to integrate the knowledge of various disciplines, make students have more in-depth experience and improve the media literacy education system of college students are important factors to ponder upon ${ }^{[9]}$. Based on this, when formulating the education system, we should fully consider the characteristics of the school, understand the diverse needs of students and fit the diverse network culture. At the same time, in the teaching process, we should constantly adjust the education and teaching methods to meet the internal development needs of college students. For example, in order to enhance the pertinence of course teaching, teachers of different majors explain in turn, so as to improve the specialization of media literacy education and help to build a professional and perfect media literacy education system. 


\subsection{Building a platform and creating a good media atmosphere}

Teachers should not only organize students to participate in campus media practice activities, but also organize students to regularly observe and study in network companies or website studios, so that they can directly involve in the creation and dissemination of network information, familiarize with the media and enhance their rational cognition. Of course, in addition to the campus, a good media atmosphere should also be reflected in practical activities of the society. In view of the current social hotspots and difficult problems, we should use modern media to carry out more in-depth practical activities, give full play to our own strength and get to know the application of our media in the society ${ }^{[10]}$. For example, how to use selfmedia for fund-raising is a problem that students can address independently. Only through personal experience and real practice can we form correct life values and good media literacy.

\section{Conclusion}

In conclusion, with the rapid development of self-media, college students do not improve their media level, but indulge in it, and rely too much on it; as a result, it is difficult to distinguish between true and false, putting the form of media literacy education for college students to the test. Therefore, colleges and universities should strengthen the education of college students' media literacy, create a good media environment for them, innovate educational methods, broaden educational paths, help students establish correct life values, and cultivate professional talents with both morality and ability as well as all-round characters.

\section{Funding}

This paper is the first batch of research topics of Shaanxi University Network Ideological and political work center (Topic: Research on the path of media literacy education for college students in the self-media environment; No.: Phased achievements of 2021spwskt-c-51).

\section{Disclosure statement}

The authors declare that there is no conflict of interest.

\section{References}

[1] Zhong HL, 2021, Analysis on the Path of Media Literacy Education for College Students in the New Era -- On the Integration and Management of News Media: An Industry Perspective. Chinese Journal of education, 2021(12): 133.

[2] Li PY, Tian H, 2021, Research on the community path of College Students' Media Literacy Education. Young Reporter, 2021(16): 43-44.

[3] Gan T, 2021, On Media Literacy Education of College Students from the Perspective of National Culture Communication. News Research Guide, 12(14): 131-132.

[4] Gu X, 2021, Research on Media Literacy Education of College Students in the New Media Era. Decision Exploration (Middle), 2021(07): 73-74.

[5] Dong ZL, 2021, Cultivation Strategies of College Students' Media Literacy from the Perspective of Self-Media. Journal of Ningxia Normal University, 42(6): 104-107.

[6] Chen AH, 2021, On the Application of Participatory Teaching Method in the Practical Teaching of Online Media Specialty. Communication and Copyright, 2021(5): 110-112. 
[7] Xu F, 2021, Interactive Integration of Ideological and Political Education and College Students' Media Literacy Education. Science, Education and Culture Collection (Next Ten Days), 2021(5): 24-26.

[8] Huang YJ, 2021, Self-Media and Media Literacy of College Students' Ideological and Political Education and Related Problems. Cultural and Educational Materials, 2021(09): 88-89, 31.

[9] Li LL, 2020, Reflections on College Students' Ideological and Political Education in the Context of Self Media. Journal of Heilongjiang Institute of engineering, 34(6): 64-67.

[10] Fan YH, 2020, Investigation and Path Exploration of Media Literacy Education of Higher Vocational College Students in the Era of Self-Media. Hebei Vocational Education, 4(06): 72-75, 99. 